\title{
Blood culture result profile and antimicrobial resistance pattern: a report from neonatal intensive care unit (NICU), Asella teaching and referral hospital, Asella, south East Ethiopia
}

\author{
Abebe Sorsa ${ }^{1 *}$, Jonas Früh², Stötter Loraine ${ }^{2}$ and Sileshi Abdissa ${ }^{1}$
}

\begin{abstract}
Background: Antimicrobial resistance is one of the major public health emergencies worldwide, and this trend didn't spare developing countries like Ethiopia. The objective of this study was to evaluate patterns of bacterial isolates and local antimicrobial susceptibility patterns in neonatal sepsis.
\end{abstract}

Methods: A hospital based observational study was conducted from April 2016 to May 2017 in Asella teaching and referral hospital (ATRH). A total of 303 neonates with clinical sepsis were included. Collected data were entered into EPI-INFO version 3.5.1 for cleanup; and then exported to SPSS version 21 for further analysis. Frequencies and proportion were used to describe the study population in relation to relevant variables.

Results: Bacterial growth was detected in 88 (29.4\%) of blood cultures. Predominantly isolated bacteria were coagulase negative staphylococci (CoNS) 22 (25\%), Escherichia coli (E.Coli) 18 (20.5\%) and Staphylococcus aureus 16 (18\%). Resistance rates of S. aureus and CoNS against Ampicillin were 11 (69\%) and 20 (91\%) respectively. The resistance rate of E. coli against Ampicillin and Gentamycin were 12 (66.7\%) and 10 (55.6\%) while Klebsiella spp. resistance rate gets much higher against these two first line antibiotics [10 (91\%) and 9 (82\%) respectively]. Similarly, both Gram-positive and Gram-negative bacteria isolates were also highly resistant to third generation Cephalosporins, and 63 (72\%) isolated bacteria showed multidrug-resistance. However; Gram-positive bacteria isolates had better susceptibility patterns to third line antibiotics like Clindamycin, Vancomycin and Ciprofloxacin while Gram-negative isolates had a higher susceptibility to Ciprofloxacin and Amikacin.

Conclusion: CoNS, S. aureus, E. coli and Klebsiella spp. were the leading bacterial causes of neonatal sepsis in our study. They were highly resistant to first- and second-line empiric antimicrobial treatment used at NICU (Neonatal intensive care unit), reducing the antimicrobial choices for management of neonatal sepsis. Fortunately, the mentioned isolated bacteria remained susceptible to third line antibiotics used to treat neonatal sepsis.

Keywords: Bacteria isolates, Neonatal sepsis, Antimicrobial resistance

\footnotetext{
* Correspondence: nathanabebe08@gmail.com

${ }^{1}$ Arsi University Asella College of Health Science, Asella, Ethiopia

Full list of author information is available at the end of the article
}

(c) The Author(s). 2019 Open Access This article is distributed under the terms of the Creative Commons Attribution 4.0 International License (http://creativecommons.org/licenses/by/4.0/), which permits unrestricted use, distribution, and reproduction in any medium, provided you give appropriate credit to the original author(s) and the source, provide a link to the Creative Commons license, and indicate if changes were made. The Creative Commons Public Domain Dedication waiver (http://creativecommons.org/publicdomain/zero/1.0/) applies to the data made available in this article, unless otherwise stated. 


\section{Background}

Neonatal mortality contributes significantly to the infant mortality rates in developing countries, various conditions are responsible for neonatal mortality among which neonatal sepsis accounts for variable figures ranging from 26 to $50 \%$ [1-4]. Neonatal sepsis is defined as any sepsis diagnosed during the first 28 days of life and further sub classified as early onset neonatal sepsis if signs and symptoms of sepsis appeared within the first six days of life and classified as late onset sepsis if clinical features of sepsis are presented between 7 and 28 days of age [5]. Neonatal sepsis is mainly caused by different Gram-positive and Gram-negative bacteria and few cases by fungi like candida species. There is a significant geographical diversity of bacteria causing neonatal sepsis and the spectrum is constantly changing over time, even in the same place [5-7]. Antibiotic resistance has become a global threat. Reports of multidrug-resistant bacteria causing neonatal sepsis in developing countries are increasing, particularly in intensive care units. The clinical signs and symptoms of neonatal sepsis are subtle and nonspecific, making early diagnosis difficult and leading to high rate of empiric antibiotic utilization which could contribute for the selection and spread of antimicrobial resistant strains of bacteria. Knowing the causative agents of neonatal sepsis and their antimicrobial sensitivity patterns could enable to choose appropriate therapy for neonatal sepsis. Targeted antibiotic therapy plays a significant role in reduction of antimicrobial resistance $[5,6]$.

The objective of this study was to assess the etiology of neonatal sepsis and to provide local antimicrobial susceptibility patterns in the neonatal intensive care unit.

\section{Methods}

A hospital-based observational study was conducted from April 2016 to May 2017at Asella teaching and referral hospital (ATRH) being a federal referral hospital located in Arsi zone, Oromia region, south east Ethiopia. The neonatal intensive care unit (NICU) is one of the wards with the highest performance of the hospital with the admission of close to 1200 neonates per year. Microbiology, hematology and biochemistry diagnostic laboratory services are available around the clock.

Sample size was calculated based on prevalence reports of neonatal sepsis from different studies ranging from 20 to $40 \%$ [1, 8-10]. By applying single population proportion and allowing $5 \%$ margin of error (d), with $95 \%$ CI $\quad(\mathrm{z} \alpha / 2=1.96) ; \mathrm{n}=(\mathrm{Za} / 2)^{2} \quad \mathrm{P}(1-\mathrm{P}) / \mathrm{d}^{2}=(1.96)^{2}$ $0.3\left(0.7 /(0.05)^{2}=322\right.$.

During the study period a total of 901 neonates were admitted to NICU from which the study participants were selected based on WHO neonatal sepsis screening tool augmented with national Neonatal Intensive Care
Unit Manual [5, 7]. Neonates meeting the inclusion criteria but being too critically ill to undergo the necessary laboratory evaluation and other procedures were excluded. Accordingly, data of 19 neonates were excluded and a total 303 study subjects were analyzed.

\section{Operational definition}

Early onset sepsis (EONS): Sepsis diagnosed in the first six days of life [5, 7].

Late onset sepsis (LONS): Sepsis diagnosed between age of 7 to 28 days of life $[5,7]$.

Premature rupture of membrane (PROM): rupture of membrane before onset of labor [5, 7].

Prolonged premature rupture of membrane (PROM): PROM lasting for more than $18 \mathrm{~h}[5,7]$.

Prolonged labor: Total duration of labor for more than $24 \mathrm{~h}[5,7]$.

Low Apgar Score: Apgar score less than seven [5, 7, 11]. First-line antibiotics: Ampicillin and Gentamycin [5, 7, 11].

Second-line antibiotics: Third generation Cephalosporins $[5,7,11]$.

Third-line antibiotics: Vancomycin, Amikacin, and Ciprofloxacin $[5,7,11]$.

A standardized questionnaire was prepared by reviewing relevant literatures and neonatology text books and translated to local Amharic language to capture demographic data, risk factors and clinical features of sepsis. After the neonates were enrolled in the study, the mothers were interviewed at a convenient, comfortable and confidential area.

Blood cultures are the gold standard test for the diagnosis of blood stream infection and should be performed in all cases of suspected sepsis prior to administering antibiotics. Accordingly, blood cultures were taken of neonates with clinical diagnosis of. Under preferably aseptic techniques a blood sample was collected by trained laboratory technicians: The laboratory technicians wore sterile gloves during the procedure and prepared a patch of skin approximately $5 \mathrm{~cm}$ in diameter over the proposed site of veni-puncture. This area was cleansed thoroughly with $70 \%$ isopropyl alcohol, followed by povidone-iodine, and followed again by alcohol. The skin was allowed to dry for at least $1 \mathrm{~min}$ before veni-puncture. One-mL sample of blood was drawn from a fresh veni-puncture site and added to a bottle containing $5-10 \mathrm{~mL}$ of blood Agar culture media. The blood cultures were incubated aerobically at $37^{\circ} \mathrm{C}$ and observed daily for consecutive three days for preliminary results by checking the presence of one of the following findings on culture media: hemolysis, air bubbles (gas production), and coagulation of broth [12]. At the same time, subcultures were made during three successive days on enriched and selective media including blood agar, chocolate agar, MacConkey agar and mannitol salt agar plates and examined for growth after $24-48 \mathrm{~h}$ of 
incubation. Showing no growth on the 7th day, blood cultures were reported as sterile. Isolated bacteria were identified using different standard techniques like Gram stain reaction, biochemical reaction properties (Lactase, Catalase, Indolase), morphological and colony characteristics [12]. Antimicrobial sensitivity testing was performed by Kirby Bauer diffusion method using Mueller Hinton agar with incubation of $24 \mathrm{~h}$ at $37^{\circ} \mathrm{C}$. according to Clinical Laboratory Standard Institute standards (CLSI) [8].

Testing was done for antibiotics used for first-, secondand third-line treatment in neonatal sepsis at ATRH [8]. The following antibiotic discs were used: Ampicillin $(10 \mu \mathrm{g})$, Cloxacillin $(5 \mu \mathrm{g})$, Gentamicin $(10 \mu \mathrm{g})$, Amikacin $(30 \mu \mathrm{g})$, Chloramphenicol $(30 \mu \mathrm{g})$, Ceftriaxone $(30 \mu \mathrm{g})$, Ciprofloxacin $(5 \mu \mathrm{g})$, Vancomycin $(30 \mu \mathrm{g})$, Clindamycin $(2 \mu \mathrm{g})$ and Erythromycin $(15 \mu \mathrm{g})$.

Data was entered into EPI-INFO version 3.5.1 for cleanup and anthropometric interpretation; and then, data were exported to SPSS version 21 edition for further analysis. Frequencies, proportion and summary statistics were used to describe the study population in relation to relevant variables. $P$-values $<0.05$ were considered statistically significant.

\section{Results}

A total of 303 (33.6\%) neonates were admitted with the diagnosis of clinical sepsis of which 88 (29.4\%) were culture proven. From those with culture confirmed neonatal sepsis, male constituted for 52 (59.1\%) while females were 36 (40.9\%). When looking at bacteria isolates disaggregated to the age of neonates at presentation, 37 (42.4\%) bacteria isolates were identified from EONS while 54 (61.2\%) from LONS which is statistically significant $(p=0.001)$. neonates born to mother who took antibiotic during labor and delivery were having two-fold reduced risk of acquiring EONS compared to LONS [AOR 2.02 (95\% CI 1.17-3.50, $p=0.011$ ]. Eight $(9 \%)$ neonates with culture proven sepsis were born at home while 80 (91\%) were born at a health institution (health center or hospital). Babies with low 5th minute Apgar score had high associated with culture confirmed neonatal sepsis [AOR 2.10 (95\% CI 1.18-3.73, $p=0.001$ ].

\section{Patterns of isolated organism}

Gram-positive bacteria accounted for 49 (55.7\%) while the remaining 39 (44.3\%) were Gram-negative bacteria. Most Gram-positive [33 (67.3\%)] bacteria were reported from neonates with clinical diagnosis of LONS at the time of presentation $(p=0.001)$. About $23(63.3 \%)$ of bacterial isolates from EONS were Gram-negative while close to two-third of identified bacteria from LONS were Gram-positive (Table 1). When disaggregating to specific bacteria pathogen; CoNS $(22,25 \%)$ and E. coli $(18,20.5 \%)$ were by far the leading causes of neonatal sepsis in our study.
Table 1 Cross tabulation showing distribution of isolated bacteria based on the age at time of sepsis diagnosis, NICU, ATRH, May 2016-April 2017

\begin{tabular}{llll}
\hline Isolated bacteria & EONS, n (\%) & LONS, n (\%) & p value \\
\hline CoNS1 & $5(22.7)$ & $17(77.3)$ & 0.001 \\
E. coli & $12(66.7)$ & $6(33.3)$ & \\
S. aureus2 & $3(18.7)$ & $13(81.3)$ & \\
Klebsiella spp. & $4(36.4)$ & $7(63.6)$ & \\
Enterobacter spp. & $2(28.6)$ & $5(71.4)$ & \\
Enterococcus spp. & $3(50)$ & $3(50)$ & \\
Citrobacter spp. $_{\text {others }}{ }^{\mathrm{a}}$ & $1(33.3)$ & $2(66.7)$ & \\
\hline CoNs1, Coaulase & $3(60)$ & $2(40)$ &
\end{tabular}

CoNS1, Coagulase negative staphylococcus $\mathrm{S}$. aureus2, staphylococcus aureus a Include: Streptococcus pneumoniae, Listeria monocytogenes and candida

\section{Sensitivity patterns of isolated bacteria Gram-positive bacteria}

Most Gram-positive bacteria isolates were from LONS, possibly being hospital acquired infections. These bacteria were highly resistant to first-line and second line antibiotics (Ampicillin and Gentamycin) and third generation cephalosporins used at NICU. The resistance rates of CoNS, S. aureus and Enterococcus against Ampicillin were 20(91\%), $11(69 \%)$ and $2(33.3 \%)$ respectively (Table 3$)$. Similarly, the resistance rates of these three organisms to Gentamycin were 14(63.6\%), 9(56.6\%) and 4(66.7\%) respectively. Identified Gram positive bacteria were also highly resistant to third generation cephalosporins with a cumulative resistance rate against Ceftriaxone, Ceftazidime and Cefotaxime being 29(60\%), 23(47\%), and 31(64\%) respectively.

Isolated Gram-positive bacteria showed better susceptibility patterns for Vancomycin, Clindamycin, Ciprofloxacin and Chloramphenicol (Table 2). Significant methicillin resistance rate was detected in Staphylococcus aureus and CoNS which were $11(69 \%)$ and $22(100 \%)$ respectively.

\section{Gram-negative bacteria}

In the current study, isolated Gram-negative bacteria were also highly resistant to commonly used empiric antibiotics at our NICU (Table 3). E. coli and Klebsiella species were extremely resistant to Ampicillin [12(66.7\%) and $10(91 \%)$ respectively]. Similarly, these bacteria were also highly resistant against Gentamycin [11(55.6\%) and 9(82\%) respectively].

E. coli and Klebsiella resistance rates against Cefotaxime, one of the commonly used third- generation Cephalosporin at our NICU were also high. Chloramphenicol, Ciprofloxacin and Amikacin showed more effectiveness against identified Gram-negative bacteria.

\section{Multidrug-resistant (MDR) bacterial isolates}

Most bacterial isolates from blood culture were found to be multidrug-resistant, mainly against first- and second-line 
Table 2 Antimicrobial resistance patterns of isolated Grampositive bacteria at NICU; ATRH. April 2016-May 2017

\begin{tabular}{llll}
\hline & CoNS & S. aureus & Enterococcus spp. \\
& $\mathrm{n}(\%)$ & $\mathrm{n}(\%)$ & $\mathrm{n}(\%)$ \\
\hline Ampicillin & $20(91)$ & $11(69)$ & $2(33.3)$ \\
Gentamycin & $14(63.6)$ & $9(56)$ & $4(66.7)$ \\
Ceftriaxone & $16(73)$ & $9(56)$ & $3(50)$ \\
Ciprofloxacin & $8(36.2)$ & $4(25)$ & $1(16.7)$ \\
Cotrimoxazole & $16(73)$ & $11(69)$ & $4(66.7)$ \\
Vancomycin & $6(27.3)$ & $3(19)$ & $1(16.7)$ \\
Chloramphenicol & $10(45.5)$ & $6(37)$ & $2(33.3)$ \\
Clindamycin & $4(18)$ & $3(12)$ & $2(33.3)$ \\
Erythromycin & $15(68)$ & $9(56)$ & $5(66.7)$ \\
Cloxacillin & $22(100)$ & $11(69)$ & $\mathrm{NT}^{\mathrm{a}}$ \\
\hline
\end{tabular}

${ }^{\mathrm{a} N T}$, not tested

antibiotics. About two-third of E. coli, 10(91\%) of Klebsiella spp., 6(85.7\%) of Enterobacter spp and 3(50\%) of Enterococcus spp. were reported to be MDR.

\section{Discussion}

In the current study, about one third of the total neonatal admissions were due to clinical sepsis with or without bacterial growth in blood cultures still remains the most important cause of neonatal morbidity. This finding is consistent with reports from other developing countries [1-3]. The rate of blood culture confirmed neonatal sepsis were significantly lower among neonates with EONS than neonates with LONS. One possible explanation for the difference in blood culture results could be because of the routine utilization of antibiotics during obstetric care which might affect the blood culture yield of the neonates as there is significant transplacental transfer of these antibiotics to the fetus. Gram-positive bacteria were the most commonly isolated organisms causing neonatal sepsis in this finding which is in congruent with study reports from Egypt, Uganda and other developing countries $[3,4,9,13,14]$.
Babies with low $5^{\text {th }}$ minutes Apgar score had high risk of developing culture-confirmed Gram-positive neonatal sepsis which could be explained by the fact that most neonates with low Apgar score might undergo extensive manipulation and resuscitation predisposing them for possible invasive colonization with Gram-positive bacteria. Also, this finding is in accordance with studies from Ethiopia and Tanzania $[1,2]$. The majority of the isolates were found in LONS, being previously described in a study from Tanzania- Muhimbili which reported S. aureus as the leading cause of neonatal sepsis [1, 15]. Similar findings were reported from Egypt, Tanzania, Uganda, Ethiopia and other developing countries which showed Gram-positive bacteria as predominant isolates causing neonatal sepsis $[6,7,11$, 16-18].

Guidelines on neonatal sepsis management in most centers $[7,19]$ recommend Ampicillin and Gentamycin as first-line empiric therapy. Unfortunately, most identified bacteria were highly resistant in this current report. Egypt and India [6,7] showed high resistance rates of isolated bacteria against Ampicillin (85-95\%) and Gentamycin $(57.3-72 \%)$. The demonstrated high rate of antimicrobial resistance (AMR) could be indicating overutilization of the named drugs as empiric treatment for most other common neonatal problems which were not actually infectious in origin. Additionally, most neonates with culture proven bacteremia were born at a health institution where most neonatal sepsis is arising from hospital acquired infections. Resistance rates of isolated Gram-positive bacteria against third generation Cephalosporines were also high in our study which is consistent with studies from Nigeria, Tanzania, Georgia, Iran and other developing countries [11, $12,15,17,19-23]$.

Methicillin resistant S. aureus (MRSA) and MDR against both, Gram-positive and Gram-negative bacteria isolates were very high in our study finding which is in agreement with most studies $[1,2,17,18,24]$.

Our study demonstrated a better susceptibility of isolated Gram-positive bacteria against Vancomycin, Clindamycin

Table 3 Antimicrobial resistance patterns against selected gram-negative bacteria; at NICU, ATRH. April 2016-May 2017

\begin{tabular}{|c|c|c|c|c|}
\hline & $\begin{array}{l}\text { E.coli } \\
n(\%)\end{array}$ & $\begin{array}{l}\text { Klebsiella spp } \\
\mathrm{n}(\%)\end{array}$ & $\begin{array}{l}\text { Citrobacter } \\
\mathrm{n}(\%)\end{array}$ & $\begin{array}{l}\text { Enterobacter spp } \\
\mathrm{n}(\%)\end{array}$ \\
\hline Ampicillin & $12(66.7)$ & $10(91)$ & $N T^{a}$ & $6(85.5)$ \\
\hline Gentamicin & $10(55.6)$ & $9(82)$ & $2(66.7)$ & $6(85.7)$ \\
\hline Cefotaxime & $11(61.1)$ & $9(82)$ & $1(33.3)$ & $3(43)$ \\
\hline Ciprofloxacin & $5(22.3)$ & $3(27)$ & $1(33.3)$ & $2(28.6)$ \\
\hline Cotrimoxazole & 11 (63.6) & $8(73)$ & $N T^{a}$ & $5(71.4)$ \\
\hline Chloramphenicol & $8(50)$ & $6(56)$ & $N T^{a}$ & $N T^{a}$ \\
\hline Amikacin & $4(22.2)$ & $4(36)$ & $N T^{\mathrm{a}}$ & $3(43)$ \\
\hline Erythromycin & $12(66.7)$ & $9(72)$ & $N T^{a}$ & $N T^{a}$ \\
\hline
\end{tabular}

${ }^{a}$ Not tested 
and Ciprofloxacin, which is also supported by the study from India and other reports $[1-4,9,13,15,17,24]$. This could be explained by less utilization of these antibiotics for two reasons: First, the antibiotics are used as third line options indicating less utilizations of these agents at NICU. Second, Ciprofloxacin is not validated to use among younger children unless benefit-risk analysis warrants its utilization and, Amikacin is not easily accessible in most centers showing its lower rate of utilization making most isolated bacteria better susceptible to these two antibiotics. Still about one-fifth of isolated S. aureus were found to be resistant for vancomycin which is in contrary with study findings from Vietnam and Egypt showed no resistance strains of S. aureus against Vancomycin [7, 21]. This could be explained by increasing trends of utilization of this antibiotic as third line because most first-line and second-line antimicrobial agents have been failing which is in line to other study findings $[5,10,11,21$, 22, 25-27], E. coli and Klebsiella spp. the two predominant Gram-negative bacteria isolates in our study, were highly resistant to Ampicillin, Gentamycin and third generation Cephalosporines. Better susceptibility of E. coli and Klebsiella spp. for Ciprofloxacin and Amikacin were reported in our study which have been also demonstrated in other study findings [11, 16]. These two drugs could be a potential antibiotic of choice for empiric treatment of neonatal sepsis in the future.

\section{Limitations of the study}

Some of the study participants were referred to our hospital and might have been partially treated or their mothers might have received antibiotics during labor and delivery which could significantly affect the yield of blood culture. There was no consideration of isolating anaerobic bacteria, which may cause neonatal sepsis rarely [6, 7, 24, 28]. CoNS isolated in early neonatal sepsis may be due to contamination during blood collection. Extended beta lactamase resistant strains were not determined since there was limited availability of biochemical tests (e.g. IMVIC, MR-VP, different sugar tests, KIA) to solidify the research output and furthermore, molecular methods were not available.

\section{Conclusion}

CoNS, S. aureus, E. coli and Klebsiella spp. were the leading causes of neonatal sepsis in our study finding. These bacteria isolates were highly resistant to first- and second-line empiric antimicrobials used at NICU contracting antimicrobial choices for management of neonatal sepsis. Third line antibiotics relatively effective against isolated bacteria. High utilization rate of antibiotics is the most important contributory factor for the development of AMR and continuous surveillance is needed in order to keep national guidelines on antimicrobial therapy updated.

\section{Abbreviations}

AMR: Antimicrobial resistance; ATRH: Asella Teaching and Referral Hospital; CONS: Coagulase negative staphylococcus aureus; CPAP: Continuous positive airway pressure; EONS: Early onset neonatal sepsis; LBW: Low birth weight; LONS: Late onset neonatal sepsis; LP: Lumber puncture; MDR: Multidrugresistant; MRSA: Methicillin resistance S. aureus; NCCLS: National Committee for Clinical Laboratory Standards; NICU: Neonatal intensive care unit; S. aureus: Staphylococcus aureus; SVD: Spontaneous vaginal delivery; WBC: White blood cell count; WHO: World health organization

\section{Acknowledgements}

The authors would like to thank Arsi University College of Health Science for funding the project and allowing us to conduct the study. We would like to extend our heartfelt gratitude to all laboratory team members for their immense expertise contribution during the study period. Lastly but not least, it is my pleasure to thank Dr. Abayneh Girma for his unreserved constructive inputs to finalize this manuscript.

\section{Funding}

Arsi University funded the study starting from data collection, analysis and interpretation.

\section{Availability of data and materials}

The datasets generated and/or analysed during the current study are not publicly available due the rules and regulations of the university but are available from the corresponding author on reasonable request.

\section{Authors' contribution}

AS, JF, LS, SA involved in the preparation of the proposal and study design, participated in data collection, data entry and data analysis as well as manuscript preparation. All authors read and approved the final manuscript.

\section{Ethics approval and consent to participate}

The research proposal was presented and approved by the Institutional Review Board of Arsi University and ethical clearance was obtained with ethical clearance certificate number of CoHS/CS/001/2016/17. Individual verbal consent of participation was obtained from mothers/ care givers of eligible neonates before starting interviews/laboratory sampling. The participation was purely voluntary and confidentiality and privacy were maintained by conducting interviews in separate spaces whenever possible. Benefits of the laboratory test were clearly communicated to mothers/care givers and for patients whose blood culture results showed positive growth, susceptibility-based antibiotics were started.

\section{Consent for publication}

Not applicable.

\section{Competing interests}

The authors declare that there is no competing and conflict of interests.

\section{Publisher's Note}

Springer Nature remains neutral with regard to jurisdictional claims in published maps and institutional affiliations.

\section{Author details}

${ }^{1}$ Arsi University Asella College of Health Science, Asella, Ethiopia.

${ }^{2}$ Hirsch-Institute of Tropical Medicine, Asella, Ethiopia.

Received: 15 December 2018 Accepted: 1 February 2019

Published online: 20 February 2019

\section{References}

1. Tumaini VM, Francis F, Mecky I, et al. Neonatal sepsis at Muhimbili National Hospital, Dar Es Salaam, Tanzania; aetiology, antimicrobial sensitivity pattern and clinical outcome. BMC Public Health. 2012;12(904):2-5.

2. Tsehaynesh G, Feleke M, Setegn E, et al. Bacterial etiologic agents causing neonatal sepsis and associated risk factors in Gondar Northwest Ethiopia. BMC Pediatrics. 2017;17(137):1-5.

3. Tilahun T, Seida M, Yibeltal T, et al. Clinical outcome and risk factors of neonatal sepsis among neonates in Felege Hiwot referral hospital, Bahir Dar, Amhara regional state North West Ethiopia. BMC Res Notes. 2017;10(265):1-6. 
4. Alexandra YK, Do HTC, Cam NP, et al. Neonatal bloodstream infections in a pediatric hospital in Vietnam: a cohort study. J Tropical Pediatrics. 2013:59(6):1-7.

5. Vergnano S, Sharland M, Kazembe P, Mwansambo C, et al. Neonatal sepsis: an international perspective. Arch Dis Child Fetal Neonatal Ed. 2005;90:220-4.

6. Bambala PZ, Vishnu B, Belgode NH, et al. Neonatal sepsis in a tertiary Care Hospital in South India: bacteriological Profile and antibiotic sensitivity pattern. Indian J Pediatr. 2010;10(5):1-5.

7. Richard A. P and the committee on fetus and newborn. Management of Neonates with suspected or proven early-onset bacterial sepsis. AAP. 2012; 129(5):1006-12.

8. Federal Ministry of Health of Ethiopia. Neonatal Intensive Care Unit Manual, 2014:73.

9. Nino M, Ekaterina K, Maia B, et al. Etiology of neonatal blood stream infections in Tbilisi, republic of Georgia. International J of Infect Dis. 2009;13: 499-505.

10. Bhagyashri B, Clinical Profile SS. Risk factors in neonatal sepsis. Journal of Dental and Medical Sciences. 2017;16(12):75-9.

11. Barrow Gl, Feltham RKA. Cowan and Steel's manual for identification of medical bacteria. 3rd ed. Cambridge: Cambridge University Press; 2003. p. 219-40.

12. WHO. Neonatal Sepsis. AllMS Protocol. 2014:1-9.

13. Robert M. K, Bonita F. S, Joseph W. St. G, et al. Nelson Textbook of Pediatrics. 20th ed. 1600 John F. Kennedy Blvd: Library of Congress Cataloging: 2016:909-25.

14. Shahla A, Mohammad T, Amin S, et al. Trends in incidence of neonatal sepsis and antibiotic susceptibility of causative agents in two neonata intensive care units in Tehran, I. R Iran. J of Clinical Neonatology. 2012; (3): 124-9.

15. Ramesh BY, Leslie ESL, Vandana KE. Bacterial isolates of early-onset neonatal sepsis and their antibiotic susceptibility pattern between 1998 and 2004: an audit from a center in India. Ital J Pediatr. 2011;37(32):1-5.

16. Clinical and Laboratory Standard Institute: Performance standards for antimicrobial disk susceptibility tests. Approved standard. In 11th edition document M02-A11. Wayne: Clinical and Laboratory Standards Institute; 2012:12-27.

17. Nyambura M, Heike C, Stephen EM. Antimicrobial resistance pattern: a report of microbiological cultures at a tertiary hospital in Tanzania. BMC Infect Dis. 2016;16(756):1-6.

18. Mugalu J, Nakakeeto MK, Kiguli S, et al. Etiology, risk factors and immediate outcome of bacteriologically confirmed neonatal septicemia in Mulago hospital. Uganda African Health Sciences. 2006;6(1):120-6.

19. Adediwura OA, David AO, lyabode OD, et al. Neonatal sepsis in a Nigerian tertiary hospital: Clinical features, clinical outcome, aetiology and antibiotic susceptibility pattern. Southern African J of Infect Dis. 2017;32(4):127-31.

20. Neema K, Erasmus K, Damas LM, et al. Predictors of positive blood culture and deaths among neonates with suspected neonatal sepsis in a tertiary hospital, Mwanza- Tanzania. BMC Pediatr. 2010;10(39):1-9.

21. Bich-T H, Michael P, Benoit $G$, et al. Burden of bacterial resistance among neonatal infections in low income countries: how convincing is the epidemiological evidence? BMC Infect Dis. 2015:15(127):1-12.

22. World Health Organization (WHO). Antimicrobial resistance: global report on surveillance. June. 2014:10-20.

23. Anita KMZ, Durrane T, Syed AA, Tauseef AK. Pathogens associated with sepsis in newborns and young infants in developing countries. Pediatr Infect Dis J. 2009;28(1):1-4.

24. Eman MRS, El-D MMA, El-S MRB, Ramadan H. Epidemiology of neonatal sepsis and implicated pathogens: a study from Egypt. Hindawi: BioMed Research International. 2015;15(6):1-9.

25. Daynia EB, Trusha N, Charlotte S, Peter AC. Bacterial bloodstream infections in neonates in a developing country. ISRN Pediatrics. 2012;2012:1-5.

26. Aishiya I, Asfiya F, Varsha AS, et al. Clinical and bacteriological profile of neonatal septicemia. International J of Recent Scientific Research. 2017;8(11): 21465-7.

27. Anna CS, Hannah B, Alexander AM, et al. Estimates of possible severe bacterial infection in neonates in sub-Saharan Africa, South Asia, and Latin America for 2012: a systematic review and meta-analysis. Lancet. 2014;14: $731-40$

28. Eitan NB, Fortino $\mathrm{S}$. The Latin America working group on bacterial resistance. Gram-negative infections in pediatric and neonatal intensive care units of Latin America. J Infect Dev Ctries. 2014:8(8):942-53.

\section{Ready to submit your research? Choose BMC and benefit from:}

- fast, convenient online submission

- thorough peer review by experienced researchers in your field

- rapid publication on acceptance

- support for research data, including large and complex data types

- gold Open Access which fosters wider collaboration and increased citations

- maximum visibility for your research: over $100 \mathrm{M}$ website views per year

At $\mathrm{BMC}$, research is always in progress.

Learn more biomedcentral.com/submissions 